\title{
Impact of early surgery in the active phase on long-term outcomes in left-sided native valve infective endocarditis
}

\author{
Shunsuke Funakoshi, MD, ${ }^{a}$ Shuichiro Kaji, MD, ${ }^{\text {a }}$ Atsushi Yamamuro, MD, ${ }^{\text {a }}$ Tomoko Tani, MD, ${ }^{a}$ \\ Makoto Kinoshita, MD, ${ }^{\mathrm{a}}$ Yukikatsu Okada, MD, ${ }^{\mathrm{b}}$ and Yutaka Furukawa, MD ${ }^{\mathrm{a}}$
}

Objective: We sought to evaluate the impact of early surgery in the active phase on long-term outcomes in patients with left-sided native valve infective endocarditis.

\begin{abstract}
Methods: Clinical data were retrospectively reviewed in 212 consecutive patients with left-sided native valve infective endocarditis from 1990 to 2009. Early surgery in the active phase (within 2 weeks after the initial diagnosis) was performed in 73 patients, and the conventional treatment strategy was applied in 139 patients. In the conventional treatment group, 99 patients underwent late surgical intervention. To minimize selection bias, propensity score was used to match patients in the early operation and conventional treatment groups. Major adverse cardiac event was defined as a composite of infective endocarditis-related death, repeat surgery, and recurrence of infective endocarditis during follow-up.
\end{abstract}

Results: The mean follow-up period was 5.5 years. In-hospital mortality was lower in the early operation group than in the conventional treatment group $(5 \%$ vs $13 \%, P=.08)$. For 57 propensity score-matched pairs, the estimated actuarial 7-year survivals free from infective endocarditis-related death and major adverse cardiac events were significantly higher in the early operation group than in the conventional treatment group (infective endocarditis-related death: $94 \% \pm 5 \%$ vs $82 \% \pm 5 \%, P=.011$, major adverse cardiac events: $88 \% \pm 5 \%$ vs $69 \% \pm 7 \%, P=.006$, respectively).

Conclusions: Compared with conventional treatment, early surgery in the active phase was associated with better long-term outcomes in patients with left-sided native valve infective endocarditis. Further prospective randomized studies with large study populations are necessary to evaluate more precisely the optimal timing of surgery in patients with native valve infective endocarditis. (J Thorac Cardiovasc Surg 2011;142:836-42)

B Supplemental material is available online.

The optimal timing of surgical intervention in patients with left-sided native valve infective endocarditis (IE) has not been clarified, and considerable controversy remains regarding the role of early surgery. Early surgical intervention in the acute or active phase of IE in the presence of uncontrolled sepsis, shock, and organ failure raises concerns about high operative mortality and risk of relapsing IE. On the other hand, postponing surgery to complete a course of antimicrobial therapy could increase embolic risk and cause extensive cardiac tissue damage, which result in more difficult repair, progressive cardiogenic shock and organ failure, and increased mortality.

From the Departments of Cardiovascular Medicine ${ }^{\mathrm{a}}$ and Cardiovascular Surgery, Kobe City Medical Center General Hospital, Kobe, Japan.

Disclosures: Authors have nothing to disclose with regard to commercial support.

Received for publication July 26, 2010; revisions received Dec 15, 2010; accepted for publication Jan 24, 2011; available ahead of print March 14, 2011.

Address for reprints: Shuichiro Kaji, MD, Department of Cardiovascular Medicine,

Kobe City Medical Center General Hospital, Kobe, Japan, 4-6 Minatojima-

nakamachi Chuo-ku, Kobe, Japan 650-0046 (E-mail: skaji@ theia.ocn.ne.jp).

0022-5223/\$36.00

Copyright $($ C 2011 by The American Association for Thoracic Surgery

doi:10.1016/j.jtcvs.2011.01.040
Recent studies have investigated the impact of surgical intervention for left-sided IE and suggested benefits of valve surgery. ${ }^{1-6}$ However, these studies were limited by a short follow-up. Moreover, improved long-term outcomes by early surgery for left-sided IE have not been clearly shown because of the lack of controlled trials and the inherent biases of observational studies. The present study compared the long-term clinical outcomes of patients with left-sided native valve IE who underwent early surgery in the active phase with patients who received the conventional treatment strategy. We tried to minimize the inherent biases in treatment selection and prognostic imbalances using propensity analyses and multivariable modeling.

\section{MATERIALS AND METHODS Study Population}

From 1990 to 2009, 212 patients with active left-sided native valve IE who were admitted to the Kobe City Medical Center General Hospital were enrolled. All patients met the modified Duke criteria for definite or possible endocarditis. For patients with multiple episodes of endocarditis, the first episode was considered as the index episode.

\section{Clinical Data}

Clinical data were retrospectively reviewed in 212 consecutive patients with IE. From medical records, we extracted data on sociodemographics, comorbid conditions, previous heart disease, microorganisms isolated, 


\section{Abbreviations and Acronyms \\ IE = infective endocarditis \\ MACE $=$ major adverse cardiac event}

echocardiographic findings, occurrence of IE complications, timing and type of cardiac surgery, euroSCORE, and outcomes. We evaluated both the additive and logistic euroSCOREs to assess the operative risk at the time of admission.

In the present study, the median time between IE diagnosis and surgery was 8 days in patients who underwent operation during the initial antibiotic therapy $(n=100)$. Of these, 50 patients underwent surgery within 7 days and 23 patients underwent surgery within 8 to 14 days after the initial diagnosis. As a result, approximately $75 \%$ of the patients underwent operation within 14 days. During the 14-day period after the initial diagnosis, the risk of embolism has been reported to be higher than after 14 days. ${ }^{7,8} \mathrm{We}$ think that surgery within this period could be a reasonable therapeutic option with the purpose of avoiding new embolic events. Thus, we defined early operation as surgical intervention within 2 weeks and late operation as surgical intervention more than 2 weeks after the initial diagnosis of IE. The indications for valve surgery in this study population were as follows: heart failure unresponsive to medical therapy, persistent infection, repeat embolization, high embolic risk, and presence of perivalvular extension of IE. In addition, the late operation was indicated in patients undergoing conventional treatment because of residual severe regurgitation after the resolution of infection. Repeat surgery was defined as the second cardiac surgery excluding the first surgical intervention for IE.

\section{Outcomes}

The end points of this study were IE-related death and major adverse cardiac event (MACE). MACE was defined as a composite of IE-related death, repeat surgery, and recurrence of IE during follow-up. Long-term outcome was determined through examination of medical records. IErelated death included cardiac death and death caused by the complications of IE, while excluding death obviously unrelated to IE, for example, death due to malignant disease and traffic accident.

\section{Statistical Analysis}

Differences between patients undergoing the early operation and patients receiving conventional treatment were compared using the chisquare test or Fisher exact test for categoric variables. Continuous variables are described as mean \pm standard deviation, except for operative days and survivals (mean \pm standard error), and compared with unpaired $t$ tests. Because operative days after the onset were not normally distributed, the Mann-Whitney $U$ test was performed to assess differences. Survival analysis was performed by Kaplan-Meier analysis, and differences in survival between groups were examined with the log-rank test.

To reduce selection bias, we performed rigorous adjustment for differences in the baseline characteristics by use of propensity score matching. By using multivariable logistic regression, a propensity score model was created to estimate the likelihood of early operation. A nearest-neighbor matching algorithm was used to match patients on the logit of the propensity score with a caliper width of 0.2 of the standard deviation of the logit of the propensity score. After propensity score matching, the baseline covariates were compared between the 2 groups with the paired $t$ test or Wilcoxon signed-rank test for continuous variables and the McNemar test for categoric variables. Survival curves were constructed with Kaplan-Meier estimates and compared with the log-rank test. For Kaplan-Meier analysis, we analyzed all clinical events by time to first event. Data analysis was performed with SPSS software (Version 17.0; SPSS, Inc, Chicago, IL).

\section{RESULTS \\ Patient Characteristics}

Of the 212 patients, 73 underwent early operation and 139 received the conventional treatment. In the conventional treatment group, 99 patients underwent late surgical intervention and 40 patients received medical treatment alone. The baseline characteristics of the early operation group compared with the conventional treatment group are summarized in Table 1. Patients in the early operation group were more likely to have aortic valve involvement, heart failure, valve perforation, and large vegetations. The euroSCORE was higher in the early operation group than in the conventional treatment group. There were no significant differences in terms of causative microorganism and cerebrovascular complications between the 2 groups, and the most common causative microorganism in both groups was Streptococcus species.

\section{Surgical Interventions}

Surgery was performed at a median of 5 days after the initial diagnosis of IE in the early operation group and at a median of 45 days in the conventional treatment group. In the early operation group $(n=73), 53$ patients had mitral valve endocarditis. Of the 53 patients, mitral valve repair was performed in $40(75 \%)$. In patients who underwent late operation in the conventional treatment group $(n=99), 69$ had mitral valve endocarditis and mitral valve repair was performed in $54(78 \%)$. When the infection involved the aortic valve, aortic valve replacement was performed in $95 \%$ of all patients. Cardiopulmonary bypass time and aorta clamp time were significantly longer in the early operation group, whereas the operative complications were comparable between the 2 groups. Table 2 summarizes the surgical procedures.

\section{Clinical Outcomes}

The in-hospital mortality was lower in the early operation group $(5 \%$ vs $13 \%, P=.08)$, whereas the operative mortality was comparable between the early operation group and the late operation group ( $5 \%$ vs $5 \%, P=.58)$.

In the conventional treatment group, 4 patients had new cerebral infarction or cerebral hemorrhage and 6 patients died during the initial hospitalization as the result of worsening heart failure and sepsis more than 2 weeks after the initial diagnosis of IE.

The mean follow-up period was $5.5 \pm 5.1$ years. There were 6 IE-related deaths and 7 non-IE-related deaths in the early operation group during follow-up, whereas there were 19 IE-related deaths and 6 non-IE-related deaths in the conventional treatment group. In addition, there were 8 repeat operations, 6 recurrences of IE, and no admission for heart failure in the early operation group, compared with 10 repeat operations, 5 recurrences of IE, and 6 admissions for heart failure in the conventional treatment group. 
TABLE 1. Baseline characteristics before propensity matching

\begin{tabular}{|c|c|c|c|}
\hline & $\begin{array}{c}\text { Early } \\
\text { operation } \\
(\mathbf{n}=73) \\
\end{array}$ & $\begin{array}{c}\text { Conventional } \\
\text { treatment } \\
(\mathbf{n}=139) \\
\end{array}$ & $\begin{array}{c}P \\
\text { value } \\
\end{array}$ \\
\hline \multicolumn{4}{|l|}{ Background } \\
\hline Age, $\mathrm{y} \pm \mathrm{SD}$ & $55 \pm 18$ & $53 \pm 17$ & .46 \\
\hline Male, $n(\%)$ & $44(60)$ & $85(61)$ & .90 \\
\hline $\begin{array}{l}\text { Date of initial diagnosis } \\
\quad(\text { year 2000-2009), n (\%) }\end{array}$ & $48(66)$ & $80(58)$ & .25 \\
\hline Hypertension, n (\%) & $14(19)$ & $34(24)$ & .38 \\
\hline Diabetes, n (\%) & $13(18)$ & $22(16)$ & .71 \\
\hline Chronic renal failure, $\mathrm{n}(\%)$ & $13(18)$ & $15(11)$ & .15 \\
\hline Hemodialysis, n (\%) & $3(4)$ & $10(7)$ & .29 \\
\hline Valvular disease, n (\%) & $24(33)$ & $65(47)$ & .05 \\
\hline Coronary artery disease, $\mathrm{n}(\%)$ & $2(3)$ & $4(3)$ & .66 \\
\hline Ejection fraction $<50 \%, \mathrm{n}(\%)$ & $6(8)$ & $7(5)$ & .26 \\
\hline \multicolumn{4}{|l|}{ Pathogens } \\
\hline Blood culture positive, n (\%) & $55(75)$ & $104(75)$ & .93 \\
\hline Streptococcus $\mathrm{sp}, \mathrm{n}(\%)$ & $33(45)$ & $70(50)$ & .48 \\
\hline Staphylococcus sp, n (\%) & $15(21)$ & $24(17)$ & .56 \\
\hline \multicolumn{4}{|l|}{ Vegetation site } \\
\hline Aortic valve, $\mathrm{n}(\%)$ & $38(52)$ & $47(34)$ & .01 \\
\hline Mitral valve, n (\%) & $53(73)$ & $103(74)$ & .81 \\
\hline $\begin{array}{l}\text { Both aortic and mitral valves, } \\
\mathrm{n}(\%)\end{array}$ & $18(25)$ & $19(14)$ & .05 \\
\hline \multicolumn{4}{|l|}{ Complication } \\
\hline Heart failure, $\mathrm{n}(\%)$ & $43(59)$ & $52(37)$ & .003 \\
\hline Valve perforation, $\mathrm{n}(\%)$ & $37(51)$ & $47(34)$ & .02 \\
\hline Cardiac abscess, n (\%) & $13(18)$ & $15(11)$ & .15 \\
\hline $\begin{array}{l}\text { Vegetation size }>10 \mathrm{~mm} \text {, } \\
\mathrm{n}(\%)\end{array}$ & $47(64)$ & $52(37)$ & $<.001$ \\
\hline Cerebral infarction, $\mathrm{n}(\%)$ & $29(40)$ & $41(30)$ & .13 \\
\hline Cerebral hemorrhage, n (\%) & $6(8)$ & $18(13)$ & .30 \\
\hline Mycotic aneurysm, n (\%) & $1(1)$ & $6(4)$ & .24 \\
\hline $\begin{array}{l}\text { euroSCORE additive, } \\
\text { points } \pm \text { SD }\end{array}$ & $6.6 \pm 3.0$ & $4.4 \pm 3.6$ & $<.001$ \\
\hline euroSCORE logistic, $\% \pm$ SD & $11.1 \pm 11$ & $6.6 \pm 9.0$ & .001 \\
\hline
\end{tabular}

Kaplan-Meier analysis shows 1, 5, and 10-year survivals of $87 \%, 85 \%$, and $79 \%$, respectively.

\section{Propensity Score Matching}

The propensity model included age, sex, hypertension, diabetes, renal failure, coronary artery disease, ejection fraction, heart valve disease, heart failure, valve involved, valve perforation, intracardiac abscess, microbial cause, vegetation size, cerebral infarction, cerebral hemorrhage, and euroSCORE. One-to-one matching was performed, and 114 patients were enrolled in the propensity-matched group. In contrast with all the patients $(n=212)$, the 2 propensity-matched groups revealed no significant differences in baseline variables (Table E1).

\section{Early Operation and Long-Term Prognosis}

In the propensity-matched patients $(\mathrm{n}=114)$, significantly fewer IE-related deaths occurred in the early
TABLE 2. Comparison of the surgical procedures between early operation and late operation

\begin{tabular}{|c|c|c|c|}
\hline & $\begin{array}{c}\text { Early } \\
\text { operation } \\
(\mathbf{n}=73)\end{array}$ & $\begin{array}{c}\text { Late } \\
\text { operation } \\
(\mathbf{n}=99)\end{array}$ & $\begin{array}{c}P \\
\text { value }\end{array}$ \\
\hline Operative timing* & $5(3-9)$ & $45(27-78)$ & $<.001$ \\
\hline \multicolumn{4}{|l|}{ Type of operation } \\
\hline Mitral valve repair, n (\%) & $29(40)$ & $45(45)$ & .45 \\
\hline Mitral valve replacement, n (\%) & $6(8)$ & $9(9)$ & .84 \\
\hline Aortic valve replacement, $\mathrm{n}(\%)$ & $20(27)$ & $23(23)$ & .53 \\
\hline $\begin{array}{l}\text { Mitral valve repair and aortic valve } \\
\text { repair, } \mathrm{n}(\%)\end{array}$ & $2(3)$ & $2(2)$ & .57 \\
\hline $\begin{array}{l}\text { Mitral valve repair and aortic valve } \\
\text { replacement, } \mathrm{n}(\%)\end{array}$ & $9(12)$ & $7(7)$ & .24 \\
\hline $\begin{array}{l}\text { Mitral valve replacement and aortic } \\
\text { valve replacement, } \mathrm{n}(\%)\end{array}$ & $7(10)$ & $6(6)$ & .39 \\
\hline Others, n (\%) & $0(0)$ & $7(7)$ & .02 \\
\hline $\begin{array}{l}\text { Cardiopulmonary bypass time, } \\
\qquad \min \pm \mathrm{SD}\end{array}$ & $181 \pm 60$ & $151 \pm 54$ & .001 \\
\hline Aortic crossclamp time, $\min \pm \mathrm{SD}$ & $132 \pm 46$ & $106 \pm 40$ & $<.001$ \\
\hline Root replacement, n (\%) & $5(7)$ & $1(1)$ & .05 \\
\hline $\begin{array}{l}\text { Mechanical valve implantation, } \\
\text { n (\%) }\end{array}$ & $19(28)$ & $22(23)$ & .50 \\
\hline \multicolumn{4}{|l|}{ Postoperative morbidity } \\
\hline Bleeding, $\mathrm{n}(\%)$ & $5(7)$ & $2(2)$ & .12 \\
\hline Acute renal failure, $\mathrm{n}(\%)$ & $4(6)$ & $1(1)$ & .10 \\
\hline Respiratory failure, $\mathrm{n}(\%)$ & $4(6)$ & $1(1)$ & .10 \\
\hline Massive pericardial effusion, $\mathrm{n}(\%)$ & $1(1)$ & $2(2)$ & .61 \\
\hline Arrhythmia, n (\%) & $2(3)$ & $0(0)$ & .18 \\
\hline Hemolysis, n (\%) & $1(1)$ & $4(4)$ & .29 \\
\hline In-hospital death, n (\%) & $4(5)$ & $5(5)$ & .58 \\
\hline Reoperation during follow-up, $\mathrm{n}(\%)$ & $8(11)$ & $10(10)$ & .86 \\
\hline $\begin{array}{l}\text { IE-related death during follow-up, } \\
\mathrm{n}(\%)\end{array}$ & $6(8)$ & $6(6)$ & .58 \\
\hline
\end{tabular}

$S D$, Standard deviation; $I E$, infective endocarditis. *Days after onset, median (25th-75th percentile).

operation group ( 2 patients, $4 \%$ ) than in the conventional treatment group (11 patients, $19 \% ; P=.012$ ) during follow-up (Table 3). As a result, the estimated actuarial 7 -year survivals free from IE-related death were 94\% \pm $5 \%$ in the early operation group versus $82 \% \pm 5 \%$ in the conventional treatment group $(P=.011$, Figure 1), and the 7-year survivals free from MACE were $88 \% \pm 5 \%$ in the early operation group versus $69 \% \pm 7 \%$ in the conventional treatment group ( $P=.006$, Figure 2$)$. The number of reoperations as well as recurrences of IE was comparable between the 2 groups (Table 3 ).

\section{Cerebral Complications and Neurologic Outcomes}

Of all the study patients, 73 had complicating stroke on admission. Diagnosis of stroke was made by computed tomography or magnetic resonance imaging. Table 4 shows the comparison of cerebral complications and neurologic outcomes between the early operation group and the conventional treatment group. Patients in the early operation 
TABLE 3. Comparison of clinical outcomes between early operation and conventional treatment groups in propensity-matched pairs

\begin{tabular}{lccc}
\hline & $\begin{array}{c}\text { Early } \\
\text { operation } \\
(\mathbf{n}=\mathbf{5 7})\end{array}$ & $\begin{array}{c}\text { Conventional } \\
\text { treatment } \\
(\mathbf{n}=\mathbf{5 7})\end{array}$ & $\begin{array}{c}\boldsymbol{P} \\
\text { value }\end{array}$ \\
\hline In-hospital death, n (\%) & $1(2)$ & $10(18)$ & .012 \\
All cause death, n (\%) & $9(16)$ & $12(21)$ & .61 \\
IE-related death, n (\%) & $2(4)$ & $11(19)$ & .012 \\
Reoperation, n (\%) & $5(9)$ & $7(12)$ & .75 \\
Recurrence IE, n (\%) & $3(5)$ & $3(5)$ & 1.00 \\
Admission for heart failure, n $(\%)$ & $0(0)$ & $3(5)$ & .25 \\
\hline
\end{tabular}

IE, Infective endocarditis.

group were more likely to have silent cerebral infarction, and patients in the conventional treatment group were more likely to have cerebral hemorrhage. The in-hospital mortality was significantly lower in the early operation group (3\% vs $26 \%, P=.01)$. In terms of neurologic outcomes, the rate of neurologic worsening was comparable between the 2 groups ( $13 \%$ vs $14 \%, P=.61)$. In the early operation group, 4 patients, including 3 with silent cerebral infarction, had postoperative neurologic worsening due to postoperative new cerebral infarction.

\section{DISCUSSION}

This study evaluated the impact of early operation in active phase on long-term outcomes in patients with left-sided native valve IE. Compared with conventional treatment, early surgery within 2 weeks after the initial diagnosis of IE was associated with better long-term outcomes. Therefore, our analysis suggests that early surgical intervention within 2 weeks may further improve clinical outcomes in patients with active left-sided native valve IE rather than conventional medical treatment.
One of the most difficult decisions in the treatment of IE is whether to recommend valve surgery in patients with active left-sided IE. Several observational studies have suggested a benefit of surgical intervention compared with conventional medical therapy alone. ${ }^{2-5}$ Vikram and colleagues ${ }^{6}$ evaluated the impact of valve surgery on 6-month mortality in left-sided IE using a propensity score analysis and concluded that valve surgery for patients with complicated IE was independently associated with reduced 6-month mortality. Conversely, Tleyjeh and colleagues ${ }^{9}$ suggested that valve surgery in left-sided IE did not provide a survival benefit but was rather associated with increased 6-month mortality. Because they did not analyze the association of timing of surgery on clinical outcome, this discrepancy might arise from a difference in operative timing. Optimal timing of valve surgery could improve the prognosis of patients with left-sided IE.

The optimal timing of valve surgery in patients with IE still remains unclear. In the surgical treatment of IE, there is always a dilemma whether to operate early to limit the risk of emboli and worsening heart failure or to delay surgery until resolution of the infection to reduce the risk of operation. Previous studies have compared the clinical outcomes between patients with and without early operation. However, the definition of early operation varied among studies from "operation during the course of antibiotic therapy" to "operation within 7 days after diagnosis of IE." Revilla and colleagues ${ }^{10}$ found no significant difference in mortality between urgent operation before antibiotic treatment has ended and elective operation at completion of antibiotic therapy. In addition, Tleyjeh and colleagues ${ }^{11}$ defined early surgery as the operation within 11 days after the diagnosis of IE and indicated that longer time to surgery from 12 to 30 days tended to be associated with better 6-month survival. Contrary to these observations, the

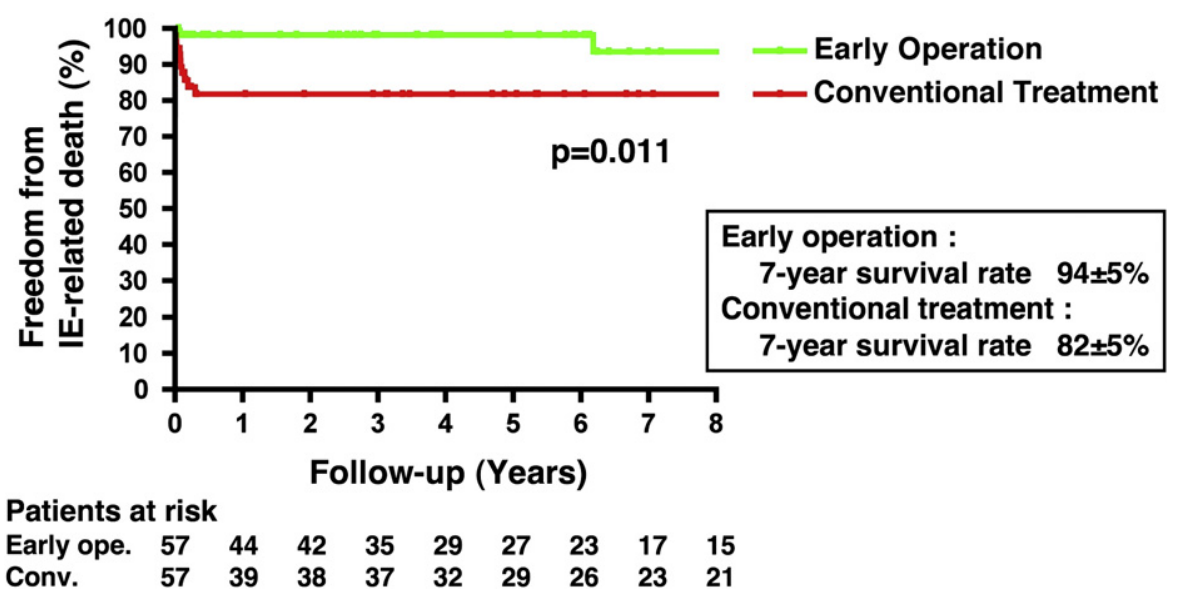

FIGURE 1. Comparison of freedom rates from IE-related death between early operation and conventional treatment groups in the propensity-matched pairs. Green line shows the survival curve in early operation group, and red line shows the survival curve in conventional treatment group. Survivals are presented as the mean value \pm standard error. $I E$, Infective endocarditis. 


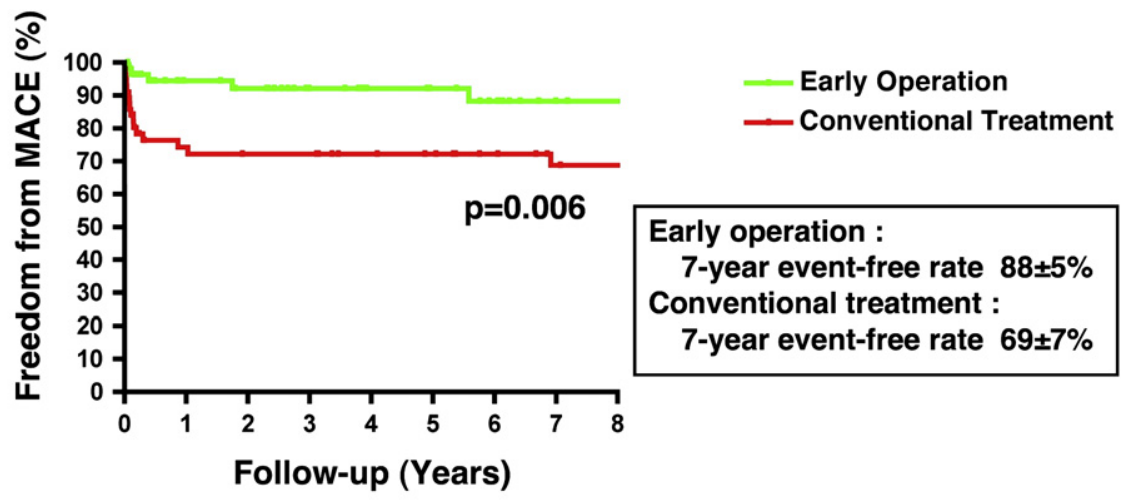

\section{Patients at risk \\ $\begin{array}{llllllllll}\text { Early ope. } & 57 & 42 & 39 & 32 & 27 & 25 & 21 & 16 & 14\end{array}$ \\ $\begin{array}{llllllllll}\text { Conv. } & 57 & 35 & 34 & 33 & 29 & 27 & 23 & 20 & 18\end{array}$}

FIGURE 2. Comparison of event-free survival between early operation and conventional treatment groups in the propensity-matched pairs. Green line shows the event-free survival curve in early operation group, and red line shows the event-free survival curve in conventional treatment group. Survivals are presented as the mean value \pm standard error. MACE, Major adverse cardiac event.

International Collaboration on Endocarditis-Prospective Cohort Study group recently found that early surgery of native valve IE was associated with an in-hospital survival benefit compared with medical therapy. They defined early surgery as the surgical intervention during the initial hospitalization for IE. ${ }^{12}$ In the present study, we defined the early operation as the surgical intervention within 2 weeks after the initial diagnosis of IE. Because the patients who underwent operation within 2 weeks after the diagnosis had better clinical outcome than patients treated with conventional strategy, the present study suggests that earlier operation may further improve long-term outcome in patients with IE.

TABLE 4. Cerebral complications and neurologic outcomes among patients with stroke

\begin{tabular}{|c|c|c|c|}
\hline & $\begin{array}{c}\text { Early } \\
\text { operation } \\
(\mathbf{n}=\mathbf{3 0})\end{array}$ & $\begin{array}{c}\text { Conventional } \\
\text { treatment } \\
(n=43)\end{array}$ & $\begin{array}{c}P \\
\text { value }\end{array}$ \\
\hline \multicolumn{4}{|l|}{ Cerebral complications } \\
\hline Cerebral infarction, $\mathrm{n}(\%)$ & $27(90)$ & $34(79)$ & .18 \\
\hline Symptomatic, n (\%) & $14(47)$ & $27(63)$ & .17 \\
\hline Silent, n $(\%)$ & $13(43)$ & $7(16)$ & .01 \\
\hline Hemorrhagic, n (\%) & $3(10)$ & $9(21)$ & .18 \\
\hline Cerebral hemorrhage, $\mathrm{n}(\%)$ & $3(10)$ & $9(21)$ & .18 \\
\hline $\begin{array}{l}\text { Cerebral hemorrhage and infarction, } \\
\mathrm{n}(\%)\end{array}$ & $2(7)$ & $7(16)$ & .20 \\
\hline Mycotic aneurysm, n (\%) & $1(3)$ & $6(14)$ & .13 \\
\hline \multicolumn{4}{|l|}{ Neurologic outcomes } \\
\hline $\begin{array}{l}\text { Postoperative cerebral infarction, } \\
\mathrm{n}(\%)\end{array}$ & $4(13)$ & $1(4)^{*}$ & .22 \\
\hline $\begin{array}{l}\text { Postoperative cerebral hemorrhage, } \\
\mathrm{n}(\%)\end{array}$ & $5(17)$ & $1(4)^{*}$ & .13 \\
\hline Neurologic worsening, n (\%) & $4(13)$ & $6(14)$ & .61 \\
\hline In-hospital death, n (\%) & $1(3)$ & $11(26)$ & .01 \\
\hline
\end{tabular}

*Among patients who underwent late operation.
There may be several rationales for careful indications of the early operation in the active phase. First, most patients who require early surgical intervention have many IErelated complications that may affect prognosis. Previous studies reported the predictors of death in patients with IE, including heart failure, embolic events, large vegetations, and intracardiac abscess. ${ }^{13-16}$ In our study, patients in the early operation group were more likely to have heart failure and large vegetations. These factors can be possible risks for the early operation. Second, antibiotic therapy can decrease the burden of microorganisms and improve the condition of the patients in the acute septic phase and reduce the operative mortality. Third, antibiotics therapy can reduce the vegetation size and risk of embolic events, such as cerebral infarction. On the other hand, there are also several benefits in early surgical intervention. The early operation can prevent the development of heart failure caused by progressive regurgitation. In addition, removal of the vegetations and infected fields by the early operation can reduce the risk of future embolic events and expansion of infection. ${ }^{17}$ Despite these potential benefits of early surgery, Thuny and colleagues ${ }^{18}$ observed that early surgical intervention for IE in the presence of sepsis can elevate the risk of relapsing IE by placing the prosthetic materials into an infected field. However, in our study, there were no significant differences in repeat operations and recurrence of IE between groups. In view of the relatively low rate of repeat operations and recurrence of infection, early surgery in the active phase could be a rational therapeutic strategy for patients with left-sided IE.

The timing of surgical intervention in patients with cerebral complications is particularly controversial. Secondary neurologic exacerbation may arise after suppression of coagulation and hypotension during extracorporeal circulation. Previous reports found that cardiac surgery should be 
postponed at least 2 to 4 weeks after cerebral complications. ${ }^{19,20}$ On the other hand, Piper and colleagues ${ }^{21}$ recently reported that cardiac surgery should be performed within 72 hours of cerebral embolism, when the risk of secondary cerebral hemorrhage seemed to be low. In addition, Shang and colleagues ${ }^{22}$ found that in patients with mitral valve IE, surgery should not be delayed because of neurologic symptoms or abnormalities on brain imaging with the exception of large hematomas. The present study found that the incidence of in-hospital death was significantly lower in patients with stroke in the early operation group than those in the conventional treatment group, although the type of concomitant stroke was different between the 2 groups. On the other hand, the incidence of neurologic worsening was comparable between the 2 groups. These results suggest that early operation for patients with cerebral complications may be an acceptable therapeutic option. However, further investigations will be required to clarify the optimal timing of the surgical intervention and identify which patient is best suited to valve surgery in patients with cerebral complications.

In the present study, the rate of mitral valve repair among patients with mitral IE in the early operation group was relatively high $(75 \%)$, considering that the feasibility of mitral valve repair in active IE has been reported to vary from 34\% to $78 \% .^{23-25}$ Because it has been reported that the incidence of reinfection was lower for patients undergoing mitral valve repair for active mitral IE compared with those undergoing mitral valve replacement, ${ }^{23}$ the higher mitral valve repair rate in our study compared with previous studies might be associated with the favorable clinical outcomes in the early operation group.

\section{Study Limitations}

The major limitations of this study are that the clinical data in this study were retrospectively reviewed and that the treatment selection was not based on a prospective randomized assignment. Although the use of propensity analysis to adjust for confounding was intended to minimize selection bias, it cannot completely control the effect of confounding. In particular, it is not possible by any study design to completely remove the selection bias associated with surgical judgment. Moreover, although we used rigorous statistical methods to adjust for the severity of disease and host-related factors, there may still be unmeasured confounding that could account for the outcomes. In addition, this study reported findings of a single center, resulting in limitations to the generalization of the results.

\section{CONCLUSIONS}

Compared with the conventional treatment, early surgery in active phase was associated with better long-term outcomes in patients with left-sided native valve IE. Further randomized studies with a large study population in multicenter settings will be required to determine the optimal timing of surgery in patients with native valve IE.

\section{References}

1. Cabell CH, Abrutyn E, Fowler VG Jr, Hoen B, Miro JM, Corey GR, et al. Use of surgery in patients with native valve infective endocarditis: results from the International Collaboration on Endocarditis Merged Database. Am Heart J. 2005; 150:1092-8.

2. Mourvillier B, Trouillet JL, Timsit JF, Baudot J, Chastre J, Regnier B, et al. Infective endocarditis in the intensive care unit: clinical spectrum and prognostic factors in 228 consecutive patients. Intensive Care Med. 2004;30:2046-52.

3. Hasbun R, Vikram HR, Barakat LA, Buenconsejo J, Quagliarello VJ. Complicated left-sided native valve endocarditis in adults: risk classification for mortality. JAMA. 2003;289:1933-40.

4. Wallace SM, Walton BI, Kharbanda RK, Hardy R, Wilson AP, Swanton RH Mortality from infective endocarditis: clinical predictors of outcome. Heart 2002;88:53-60.

5. Aksoy O, Sexton DJ, Wang A, Pappas PA, Kourany W, Chu V, et al. Early surgery in patients with infective endocarditis: a propensity score analysis. Clin Infect Dis. 2007;44:364-72.

6. Vikram HR, Buenconsejo J, Hasbun R, Quagliarello VJ. Impact of valve surgery on 6-month mortality in adults with complicated, left-sided native valve endocarditis: a propensity analysis. JAMA. 2003;290:3207-14.

7. Baddour LM, Wilson WR, Bayer AS, Fowler VGJr, Bolger AF, Levison ME, et al. Infective endocarditis: diagnosis, antimicrobial therapy, and management of complications: a statement for healthcare professionals from the Committee on Rheumatic Fever, Endocarditis, and Kawasaki Disease, Council on Cardiovascular Disease in the Young, and the Councils on Clinical Cardiology, Stroke, and Cardiovascular Surgery and Anesthesia, American Heart Association: endorsed by the Infectious Diseases Society of America. Circulation. 2005;111:e394-434

8. Vilacosta I, Graupner C, San Roman JA, Sarria C, Ronderos R, Fernandez C, et al. Risk of embolization after institution of antibiotic therapy for infective endocarditis. J Am Coll Cardiol. 2002;39:1489-95.

9. Tleyjeh IM, Ghomrawi HM, Steckelberg JM, Hoskin TL, Mirzoyev Z, Anavekar NS, et al. The impact of valve surgery on 6-month mortality in leftsided infective endocarditis. Circulation. 2007;115:1721-8.

10. Revilla A, Lopez J, Vilacosta I, Villacorta E, Rollan MJ, Echevarria JR, et al Clinical and prognostic profile of patients with infective endocarditis who need urgent surgery. Eur Heart J. 2007;28:65-71.

11. Tleyjeh IM, Steckelberg JM, Georgescu G, Ghomrawi HM, Hoskin TL, Enders FB, et al. The association between the timing of valve surgery and 6-month mortality in left-sided infective endocarditis. Heart. 2008;94:892-6.

12. Lalani T, Cabell CH, Benjamin DK, Lasca O, Naber C, Fowler VG Jr, et al. Analysis of the impact of early surgery on in-hospital mortality of native valve endocarditis. Use of propensity score and instrumental variable methods to adjust for treatment-selection bias. Circulation. 2010;121:1005-13.

13. Thuny F, Di Salvo G, Belliard O, Avierinos JF, Pergola V, Rosenberg V, et al. Risk of embolism and death in infective endocarditis: prognostic value of echocardiography: a prospective multicenter study. Circulation. 2005;112:69-75.

14. Chu VH, Cabell CH, Benjamin DK Jr, Kuniholm EF, Fowler VG Jr, Engemann J, et al. Early predictors of in-hospital death in infective endocarditis. Circulation. 2004;109:1745-9.

15. Sheikh AM, Elhenawy AM, Maganti M, Armstrong S, David TE, Feindel CM Outcomes of surgical intervention for isolated active mitral valve endocarditis. J Thorac Cardiovasc Surg. 2009;137:110-6.

16. Jaffe WM, Morgan DE, Pearlman AS, Otto CM. Infective endocarditis, 1983-1988: echocardiographic findings and factors influencing morbidity and mortality. J Am Coll Cardiol. 1990;15:1227-33.

17. Kim DH, Kang DH, Lee MZ, Yun SC, Kim YJ, Song JM, et al. Impact of early surgery on embolic events in patients with infective endocarditis. Circulation. 2010;122:S17-22.

18. Thuny F, Beurtheret S, Mancini J, Gariboldi V, Casalta JP, Riberi A, et al. The timing of surgery influences mortality and morbidity in adults with severe complicated infective endocarditis: a propensity analysis. Eur Heart J. 2009 Mar 26 [Epub ahead of print].

19. Eishi K, Kawazoe K, Kuriyama Y, Kitoh Y, Kawashima Y, Omae T. Surgical management of infective endocarditis associated with cerebral complications. Multicenter retrospective study in Japan. J Thorac Cardiovasc Surg. 1995;110:1745-55. 
20. Gillinov AM, Shah RV, Curtis WE, Stuart RS, Cameron DE, Baumgartner WA, et al. Valve replacement in patients with endocarditis and acute neurologic deficit. Ann Thorac Surg. 1996;61:1125-30.

21. Piper C, Wiemer M, Schulte HD, Horstkotte D. Stroke is not a contraindication for urgent valve replacement in acute infective endocarditis. J Heart Valve Dis. 2001;10:703-11.

22. Shang E, Forrest GN, Chizmar T, Chim J, Brown JM, Zhan M, et al. Mitral valve infective endocarditis: benefit of early operation and aggressive use of repair. Ann Thorac Surg. 2009;87:1728-34.
23. Muehrcke DD, Cosgrove DM 3rd, Lytle BW, Taylor PC, Burgar AM, Durnwald CP, et al. Is there an advantage to repairing infected mitral valves? Ann Thorac Surg. 1997;63:1718-24.

24. Iung B, Rousseau-Paziaud J, Cormier B, Garbarz E, Fondard O, Brochet E, et al. Contemporary results of mitral valve repair for infective endocarditis. J Am Coll Cardiol. 2004;43:386-92.

25. Zegdi R, Debieche M, Latremouille C, Lebied D, Chardigny C, Grinda JM, et al. Long-term results of mitral valve repair in active endocarditis. Circulation. 2005; 111:2532-6. 
TABLE E1. Baseline characteristics after propensity matching

\begin{tabular}{|c|c|c|c|}
\hline & $\begin{array}{c}\text { Early } \\
\text { operation } \\
(\mathbf{n}=\mathbf{5 7}) \\
\end{array}$ & $\begin{array}{c}\text { Conventional } \\
\text { treatment } \\
(\mathbf{n}=\mathbf{5 7}) \\
\end{array}$ & $\begin{array}{c}P \\
\text { value } \\
\end{array}$ \\
\hline \multicolumn{4}{|l|}{ Background } \\
\hline Age, $\mathrm{y} \pm \mathrm{SD}$ & $55 \pm 18$ & $52 \pm 18$ & .37 \\
\hline Male, $n(\%)$ & $34(60)$ & $36(63)$ & .83 \\
\hline Hypertension, n (\%) & $11(19)$ & $10(18)$ & 1.00 \\
\hline Diabetes, n (\%) & $10(18)$ & $10(18)$ & 1.00 \\
\hline Chronic renal failure, $\mathrm{n}(\%)$ & $7(12)$ & $9(16)$ & .77 \\
\hline Valvular disease, n (\%) & $21(37)$ & $24(42)$ & .69 \\
\hline Coronary artery disease, $\mathrm{n}(\%)$ & $2(4)$ & $2(4)$ & 1.00 \\
\hline Ejection fraction $<50 \%, \mathrm{n}(\%)$ & $2(4)$ & $3(5)$ & 1.00 \\
\hline \multicolumn{4}{|l|}{ Pathogens } \\
\hline Streptococcus sp, n (\%) & $29(51)$ & $30(53)$ & 1.00 \\
\hline Staphylococcus sp, n (\%) & $8(14)$ & $14(25)$ & .21 \\
\hline \multicolumn{4}{|l|}{ Vegetation site } \\
\hline Aortic valve, n (\%) & $29(51)$ & $28(49)$ & 1.00 \\
\hline Mitral valve, n (\%) & $39(68)$ & $40(70)$ & 1.00 \\
\hline $\begin{array}{l}\text { Both aortic and mitral valves, } \\
\mathrm{n}(\%)\end{array}$ & $11(19)$ & $13(23)$ & .80 \\
\hline \multicolumn{4}{|l|}{ Complication } \\
\hline Heart failure, $\mathrm{n}(\%)$ & $31(54)$ & $31(54)$ & 1.00 \\
\hline Valve perforation, $\mathrm{n}(\%)$ & $30(53)$ & $26(46)$ & .57 \\
\hline Cardiac abscess, n (\%) & $9(16)$ & $10(18)$ & 1.00 \\
\hline Vegetation size $>10 \mathrm{~mm}, \mathrm{n}(\%)$ & $32(56)$ & $37(65)$ & .33 \\
\hline Cerebral infarction, $\mathrm{n}(\%)$ & $20(35)$ & $24(42)$ & .58 \\
\hline Cerebral hemorrhage, n (\%) & $5(9)$ & $7(12)$ & .77 \\
\hline Mycotic aneurysm, n (\%) & $1(2)$ & $3(5)$ & .63 \\
\hline euroSCORE logistic, $\% \pm$ SD & $8.3 \pm 7$ & $9.0 \pm 11$ & .44 \\
\hline
\end{tabular}

$S D$, Standard deviation. 